\title{
Assessment Reliability of Businesses as Components in Organizational Structure of Investment Construction Projects
}

\author{
Andrey Morozenko ${ }^{1, *}$ \\ ${ }^{1}$ Moscow State University of Civil Engineering, Yaroslavskoe shosse, 26, Moscow, 129337, Russia
}

\begin{abstract}
This article is one of few attempts to get insights into business robustness metrics with a systemic approach based on improved corporate structure of construction companies. With a systemic out look, this article sets out a concept of "reliability system" as unbiased description of the system's organizational structure, highlights organizational, process flow, financial and economic, as well as social and HR systemic (internal) reliability factors of corporate structure functioning. The article also offers a technique focused on the practical use of the laid down principles of business reliability metrics based on the assumption that an absolutely robust company in a sample is the one with reliability factors not lower than the average for this sample. In order to apply the described technique, this article summarizes indicators divided into groups of reliability factors.
\end{abstract}

\section{Introduction}

The construction industry, like no other, features a well-developed system of partnerships and business relationships. A vital necessity to engage a lot of custom contractors, financial and investment structures force the organizers and project investors to select contractors and partners not just by their professional skills, but also by a whole range of business skills, especially since construction projects deal with transfers and use of considerable material resources and capital [2,9]. Therefore, it draws close attention of researchers to unbiased rating of the overall business performance indicators brought together in a concept like reliability.

Business reliability metrics largely embrace the ideas of such economists as Altman, Lisa, Teffler, etc. Estimates based on multiplicative discriminant analysis adequately reflect the financial parameters of sustainable business operations, but only in a steady, fully developed economic environment. Modern researchers expressly indicate the restrictions in the use of this method for measuring reliability of Russian construction companies [2,3,5$7,9]$. Perhaps, this explains lots of publications on reliability metrics for industrial enterprises in domestic academic works. However, as a rule, both in the Russian $[1,4,10]$ and foreign practice $[11,12,14,15]$, the offered techniques are very field-specific and focus on one aspect of production and economic operations. Thus, for example, the works deal with financial, economic, process flow reliability, although the very concept of is a system

*Corresponding author: MorozenkoAA@mgsu.ru 
icnotion and must be considered as a whole with all the properties and qualities of a business [8].

\section{Methodology}

Based on a systemic approach to this issue and armed with ideas of information technologies, let us formulate the essence of the concept named "reliability system". The research of properties and qualities of corporate structures lacks solid unity in this system's quality. A descriptive and largely intuitive approach to this one of the most crucial concepts of systemic analysis does not allow using it as an unbiased description of the system's organizational structure.

We believe that the most accurate description of this system's quality today is contained in the following statement: reliability is a property of the system's organizational structure that reflects the probability of the system performing its intended function with a given quality in a static field of external effects with changes in the internal environment $[8,16]$. Still, we are aware of the original condition of the internal environment that should be adequate to the scalar field of external effects of the system's environment. This understanding of reliability helps us measure reliability assessment reliability and factors that affect system reliability in figures.

Let us highlight the systemic (internal) factors of reliability in corporate structure.

Table 1. The most crucial factors.

\begin{tabular}{|l|}
\hline 1. Organizational factors \\
1.1. Competence of CEOs \\
1.2. Performance of corporate structure \\
1.3. Flexibility of corporate structure \\
1.4. Availability of standardized governance system \\
1.5. Availability of resolution follow-up scheme \\
1.6. Maturity of horizontal backbone links within a company \\
1.7. Special links in corporate structure \\
\hline 2. Process flow factors \\
2.1. Performance potential of core production equipment \\
2.2. Availability of modern production technologies \\
2.3. Flexibility of the production process \\
2.4. Use of modern materials \\
2.5. Modern energy infrastructure \\
2.6. Condition of production infrastructure \\
2.7. Use of research results, upgrade of fixed assets \\
2.8. Availability of production labs and research units \\
3. Financial and economic factors \\
3.1. Share of own equity \\
3.2. Leverage \\
3.3. Ratio of fixed assets to property value \\
3.4. Accounts payable in total liabilities \\
3.5. Share of working capital in total assets \\
3.6. Availability of financial resilience management system \\
3.7. Ratio of dividend returns to market deposit rate \\
3.8. Credit and financial score of a business
\end{tabular}




4. Social and HR factors
4.1. Staff motivation system
4.2. Connection of compensation with performance
4.3. Staff turnover
4.4. Lifelong learning and training
4.5. Promotion of innovation and invention
4.6. Financial and moral encouragement of best employees
4.7. Arrangement of creative contests
4.8. Social security
4.9. Business involvement in solving staff's social problems
4.10. Company's socio-manufacturing reputation

Table 1 shows the most crucial factors that determine business reliability. Despite lots of factors and indicators describing their impact on safe business operations, there are no fundamental difficulties in the calculation of production reliability as a function of resource costs aimed to compensate for the negative changes in the condition of the internal business environment as a system.

However, this time-consuming analysis is of purely academic interest able to identify trends in the development of this system's quality. A practical objective in measuring business reliability can be achieved through the following technique based on the assumption that an absolutely robust company in a sample is the one with reliability not lower than the average for this sample. Naturally, a rated sample of businesses should include successfully operating companies. Then their benchmarking should be as follows.

In the groups of reliability factors (Table 1), we identify key factors whose number may range from one to several. The main factor is to meet two requirements: reflect the impact on business reliability to the maximum extent, be expressed quantitatively in the available sources of information. Then, the reliability of each company will be determined by a combination of reliability factors:

$$
P_{n}=f\left(\begin{array}{c}
i=k \\
P \\
j=1
\end{array}\right)
$$

Here, an absolutely robust business will be the one with the following equation:

$$
P_{n}=\prod_{j=1}^{k} \Phi_{i}\left(t_{i}\right)=1
$$

Where: $\Phi_{i}$ is a business reliability factor; $\left(t_{i}\right)$ is a numeric value of $i$-factor equal to: $t_{i}=\frac{t_{j}}{T_{\text {ind }}} ;\left(t_{j}\right)$ is an overall index of a business reliability factor.

Thus, the reliability of business operations can be measured with the reliability index equal to:

$$
P_{n}=\prod_{j=1}^{k} \Phi_{i}\left(t_{i}\right)
$$

\section{Results}

It is much more complicated to measure the impact of organizational factors on business reliability in comparable terms, but as shown in [13], a corporate structure largely affects business as a system. Based on the information, let us evaluate the corporate structure by the presence or absence of crucial components. Thus, the ability to identify the system's governance and executive part in the structure helps us to assign the desired value to a relevant ratio. 
Table 2. Signs of corporate structure.

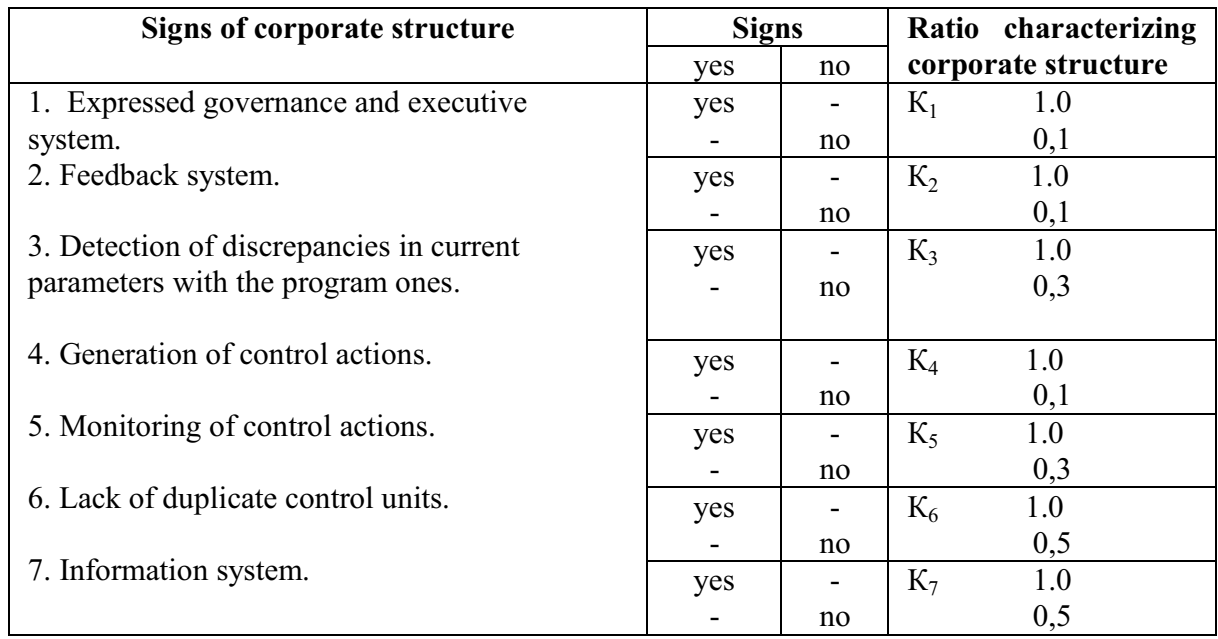

\section{Discussion}

This approach, in all the conventions of numerical expression (Table 2), presence or absence of corporate structure components, results in correct conveyance of modern outlooks onto the principles of corporate structure formation with top qualities of competitive advantage.

Thus, corporate structure reliability can be rated using the index equal to:

$$
P_{\text {n.org. }}=\prod_{j=1}^{i=j} k_{i}
$$

The source of information for determining i-ratios can be a payroll and corporate structure. To measure the impact of production and technical factors of business reliability, we have chosen the following indicators as general factors:

- return on assets;

- capital ratio of fixed assets;

- inventories in number-of-days supply;

- share of investments in plant assets.

We take these general financial and economic factors: profitability, working capital turnover, overall coverage ratio.

Social reliability factors can be characterized by the following generalizing indicators: staff turnover, performance, average level of education.

The sources of information for these metrics are contained in business statistical reports: presence and movement of fixed assets, productive capacity balance sheet, labor report, financial statements on the movement of the working capital and financial performance during the reporting period.

\section{Conclusion}

The described simple technique of unbiased corporate structure reliability metrics for construction companies will provide substantial assistance to construction stakeholders in their business. 


\section{References}

1. M.A. Batkovsky, The new science: experience, tradition, innovation 1-1(123), 8487(2017)

2. A.S. Bolotov, A.V. Ginzburg, Economy and business 10-1(75-1), 647-651(2016)

3. A.A. Volkov, S.B. Sborshikov, T.V. Hripko, Vestnik MGSU 10, 105-111 (2016)

4. A.V. Ginsburg, Industrial and Civil Engineering 9, 61-65(2016)

5. P.B. Zhavnerov, A.V. Ginsburg, Natural and Technical Sciences 6 (84), 273-275(2015)

6. N.V. Zheglova, The International scientific-practical conference proceedings, 77-81 (2015)

7. A.A. Lapidus, S.A. Feldman, Vestnik MGSU 6, 101-106 (2016)

8. A.A. Morozenko, Scientific and Technical VolgaRegion Bulletin 3, 209-213 (2013)

9. E.O. Razov, Economics and Management 8, 257-260 (2013)

10. S.A. Sinenko, T.K. Kuzmina, Scientific Review 18, 156-159 (2015)

11. L.Bukowski, Reliability Engineering and System Safety 151, 76-92 (2016)

12. S. Dahmani, X. Boucher, S. Peillon,B.Besombes, Journal of Manufacturing Technology Management27 (4), 502-534 (2016)

13. A.A. Morozenko, Applied Engineering Research 10 (21),41831-41835(2015)

14. F.V.Haase, R.Woll, Management and Production Engineering Review 7 (2), 12-20 (2016)

15. A.M. Solyman ,O.A. Ibrahim, A.A. Elhag, Electronics and Embedded Systems Engineering 7381442, 123-128 (2016)

16. V.I. Telichenko, A.A. Morozenko, Publishing House “ASV”, 510-511 (2014) 